\title{
REFLEXÃO A RESPEITO DAS CONTRIBUIÇÕES E DOS LIMITES DA HISTÓRIA DE VIDA NA PESQUISA EM ADMINISTRAÇÃO
}

\author{
REFLECTING ON THE CONTRIBUTIONS AND LIMITS OF THE LIFE HIS- \\ TORY IN BUSINESS ADMINISTRATION RESEARCH
}

Texto convidado em Junho/2017 Editor Científico: Edson Sadao Iizuka DOI 10.13058/raep.2018.v19n1.954

\section{ARILDA SCHMIDT GODOY arildagodoy@gmail.com}

UNIVERSIDADE ESTADUAL PAULISTA JÚLIO DE MESQUITA FILHO - CAMPUS DE RIO CLARO

\begin{abstract}
RESUMO
Este ensaio apresenta a modalidade de pesquisa denominada história de vida, com tal intuito, realçando alguns de seus limites e contribuições para a pesquisa em administração. Para alcançar este objetivo, o texto inicia com um breve registro das origens desse método investigativo, transcreve sua conceituação e ressalta suas contribuições fundamentais. Elenca autores que analisam tais contribuições no campo específico da investigação em administração e indica os temas mais explorados pela história de vida, nos estudos realizados em âmbito internacional e nacional. A seguir, são tratados alguns aspectos que limitam o processo analítico-interpretativo que caracteriza essa modalidade de pesquisa em administração. Para fechar o texto foi importante pontuar que a pesquisa que traz "novas cores e sabores" nem sempre tem sido valorizada na administração. No caso da história da vida, ressalta-se que esse método investigativo pode promover o esforço de autorreflexão do pesquisador de forma que ele tenha a oportunidade de transformar, recontextualizar e amplificar seus conhecimentos, com isso, podendo alterar sua visão a respeito do mundo e do seu próprio trabalho. $\mathrm{O}$ ensaio retrata o olhar da autora, a partir do qual se almeja suscitar indagações que levem a um diálogo frutífero quanto à possibilidade de ampliar a obtenção do conhecimento em administração.

Palavras-chave: História de vida. Pesquisa qualitativa. Pesquisa em administração. Contribuições e limites.
\end{abstract}

\begin{abstract}
This essay examines the research modality known as "life history" highlighting some of its contributions and limitations on the business administration research. To achieve this goal, the text starts with a brief record of the origins of this investigative method, it then presents its concept and highlights its fundamental contributions. The text also introduces authors who analyze such contributions in the specific field of the investigation in administration and shows the subjects frequently explored by the life history in studies conducted at international and national levels. The text proceeds to expose aspects that limit the analyticalinterpretative process that characterizes this type of business administration research. In the conclusion, the text points out to the fact that the research that brings "new colors and flavors" has not always been valued in the science of Administration. In the case of life history, it is emphasized that this investigative method can promote the researcher's self-reflection effort, allowing he/she the opportunity to transform, relocate and amplify his/her knowledge, changing his/her world vision and his/her own work. The essay reflects the author's perspective, from which it is expected to raise questions that lead to a fruitful dialogue about the possibility of expanding the acquisition of business administration knowledge.
\end{abstract}

Keywords: Life history. Qualitative research. Business administration research. Contributions and limitations. 
A investigação centrada na narração de histórias - denominada história de vida - é considerada uma modalidade de pesquisa qualitativa que busca responder às questões que indagam: "como" as pessoas apresentam seus argumentos ao expor suas trajetórias pessoais, "como" elas desejam se mostrar, "como" descrevem suas ações e suas vidas. Ademais, as expressões por elas compartilhadas, o vocabulário e as metáforas utilizadas podem dizer muito a respeito dos grupos sociais a que pertencem e da maneira "como" tais grupos se veem e descrevem suas experiências (GIBBS, 2009). A visão de Atkinson (2001) é esclarecedora ao pontuar que a história de vida se constitui num método de pesquisa qualitativa, de natureza interdisciplinar, que visa obter informações sobre aspectos subjetivos da vida de uma pessoa e que procura compreender tanto vivências únicas e singulares quanto focalizar os vários papéis desempenhados pelo indivíduo na sociedade.

Plummer (2001) destaca que a história de vida faz parte de um conjunto de manifestações que expressa facetas da existência das pessoas, assim, estando presente nos documentos que elas usam para "falar" a respeito de suas vidas. Pessoas registram fatos e sentimentos em diários, escrevem e enviam cartas, tiram fotografias, elaboram biografias, publicam memórias, constroem blogs e sites, compõem canções, fazem filmes e vídeos, pintam quadros, expressam-se por meio de grafites, concedem entrevistas. $\mathrm{O}$ autor entende que todas essas formas constituem-se em documentos de vida que podem ser utilizados em diferentes campos do conhecimento para registrar, analisar e interpretar relatos por meio dos quais se busca compreender o mundo dos atores sociais em seus próprios termos. Assim, o entendimento dos vários aspectos que constituem a vida de uma pessoa pode contar com diversas fontes de informação, além do relato oral.

Essa modalidade de pesquisa ganhou respeito e aceitação em vários campos do saber, tais como antropologia, sociologia, psicologia, história, educação e administração (de forma mais tímida). Embora de uso restrito no campo da administração , considera-se que a história de vida se revela promissora no avanço do conhecimento em diferentes temas desta área. Este texto examina a história de vida realçando algumas de suas possíveis 
contribuições e de certos limites na pesquisa em administração, retratando o olhar da autora, a partir do qual se espera suscitar outras indagações que levem a um diálogo frutífero sobre essa possibilidade de se ampliar a forma de obtenção do conhecimento neste campo.

Para alcançar esse objetivo é relevante iniciar com um breve registro das origens e apontar as contribuições fundamentais desse método investigativo.

De acordo com Queiroz (1991), o primeiro estudo sociológico que utilizou a história de vida foi "The Polish Peasant in Europe and America”, escrito por Thomas e Znaniecki, inicialmente, publicado entre 19181920. Posteriormente, nos anos 20 e 30 do século passado, outros trabalhos foram produzidos por pesquisadores alinhados à Escola de Chicago e ao movimento do interacionismo simbólico, conforme Godoy (2013). Sob a liderança de Robert E. Park, este grupo de pesquisadores conquistou grande popularidade para essa abordagem metodológica, que passou a ser uma das mais utilizadas no departamento de sociologia dessa universidade. Os estudos particulares sobre os chamados desviantes, como, por exemplo, a história do ladrão profissional conhecido como Chic Conwell, descrita por Sutherland e publicada pela primeira vez em1937, e do delinquente juvenil Stanley, contada por Shaw, com publicação original de 1930, articulavam-se para fornecer uma espécie de mosaico da cidade de Chicago a partir dos anos 30 do século passado (BECKER, 1994). Segundo Becker (1994), uma contribuição fundamental da história de vida é que ela atribui grande importância às interpretações que as pessoas fazem de sua própria experiência, representando uma rica via de acesso ao vivido subjetivo, ou seja, é valorizada a versão dos fenômenos construída pelos próprios atores sociais. Sendo assim, representa uma modalidade metodológica na qual os discursos, as narrativas dos sujeitos, ganham valor central para a compreensão dos fenômenos sociais.

É esse o sentido da definição de Queiroz (1991, p. 6), para quem, a história de vida representa "o relato de um narrador sobre sua existência através do tempo, tentando reconstituir os acontecimentos que vivenciou e transmitir a experiência que adquiriu". 
Na sua origem, essa perspectiva sofreu reações por parte do mainstream da sociologia estadunidense. Argumentava-se que ela apresentava resultados vagos, baixa capacidade de generalização e um diálogo insuficiente com a teoria. Era considerada pouco confiável, aproximando-se mais da literatura e do jornalismo do que do método científico, como determinavam os ditames positivistas. A preocupação de $\operatorname{Becker}(1994$, p.102) com relação a esse aspecto pode ser constatada a seguir:

Certamente não é ficção, embora os documentos de história de vida mais interessantes tenham uma sensibilidade, um ritmo e uma urgência dramática que qualquer romancista adoraria conseguir [...] As diferenças entre estas formas residem tanto na perspectiva a partir da qual o trabalho é realizado quanto nos métodos utilizados. O escritor de ficção, é claro, não se preocupa em absoluto com fatos, mas, antes, com o impacto emocional e dramático [...] A fidelidade para com o mundo como ele existe é somente um dos muitos problemas para ele, e para muitos autores este é um aspecto de importância menor [...] Comparada a estas formas mais imaginativas e humanísticas, a história de vida se aproxima mais do terra-a-terra [...] se interessa menos por valores artísticos do que por um relato fiel da experiência e interpretação por parte do sujeito do mundo no qual vive.

Todavia, pouco a pouco, a história de vida foi superando uma condição marginal e, sobretudo, a partir dos anos 80 do século passado, passou a assumir o seu lugar no rol das metodologias qualitativas.

Atkinson (2001, p. 125) esclarece que uma história de vida refere-se à narrativa "que uma pessoa escolheu contar a respeito da vida que ela tem vivido, contada tão completamente e honestamente quanto possível". O resultado é uma narrativa do que aconteceu com a pessoa num período de tempo, que vai de sua infância até o momento presente, e que ilumina as mais importantes experiências, circunstâncias, influências, temas, lições e emoções de uma existência.

Algumas distinções importantes ajudam a entender o escopo e a abrangência da história de vida, também, Plummer (2001) contribui com essa tarefa, para tanto, fazendo um contraste entre o que ele denomina his- 
tórias de vida longas e curtas. As histórias de vida longas são aquelas mais representativas do método e relatam a vida de uma pessoa em suas próprias palavras, normalmente, cobrindo longo período de tempo. É realizada a partir de uma série de entrevistas com um informante, complementada com outras fontes de informação, como, por exemplo, diários, observação intensiva da vida da pessoa, cartas e fotografias. As histórias de vida curtas, intituladas, por Demartini (1999; 2001), histórias de vida sumárias ou resumidas, são mais focalizadas, atendo-se a temas específicos, centrados num determinado aspecto da trajetória do sujeito. São, normalmente, coletadas por meio de entrevistas em profundidade, orientadas por um roteiro de questões abertas. Aqui, o pesquisador centra sua atenção num conjunto de histórias de vida que visa compor um relato mais amplo, o qual pode fazer parte de um projeto coletivo e institucional. $\mathrm{Na}$ área de administração, essa modalidade de história de vida é mais comum.

Conquanto contar histórias faça parte da sociedade e seja um ato corriqueiro em muitas situações da vida cotidiana, nem sempre relatos que ocorrem naturalmente são aproveitados e analisados pelos pesquisadores do campo das ciências humanas e sociais. O mais comum, em se tratando do mundo acadêmico, é o pesquisador recorrer ao que Plummer (2001) chama de histórias solicitadas, ou seja, aquelas obtidas a partir do interesse e do convite de um investigador que tem um objetivo de pesquisa que, normalmente, busca desvendar um aspecto teórico mais amplo. São obtidas em situações não naturais, planejadas para que os informantes colaborem com o pesquisador, desenvolvidas por meio de entrevistas, com o auxílio de roteiros previamente organizados, registradas em áudio e/ou vídeo e transcritas para análise e interpretação.

O esforço do pesquisador, nesse caso, é o de mapear e entender os caminhos por meio dos quais os atores sociais constroem e dão sentido ao seu mundo particular. Além disso, ao buscar compreender a vida de atores sociais, também, é importante entender a cultura (ou sistema de significados compartilhados) da qual ela é parte. Para Plummer (2001), é fundamental lembrar que a história de vida revela aspectos do tempo vivido pelo indivíduo, que se traduz em ciclos, fases ou estágios, assim como está conectada 
ao tempo histórico no qual essa existência está inserida. Queiroz (1991, p. 21) revela que a história de vida "capta o que sucede na encruzilhada da vida individual com o social". Essa é uma ideia compartilhada por Velho (2006, p. 17), que aponta:

Lido com indivíduos que narram suas experiências, contam suas histórias de vida para um pesquisador próximo, às vezes conhecido. As preocupações, os temas cruciais são, em geral, comuns a entrevistados e entrevistador. A conversa não é sobre crenças e costumes exóticos à socialização do pesquisador. Pelo contrário, boa parte dela faz referência a experiências históricas, no sentido mais amplo, e cotidianas também do meu mundo, às minhas aflições e perplexidades. Eu, o pesquisador, ao realizar entrevistas e recolher histórias de vida, estou aumentando diretamente o meu conhecimento sobre a minha sociedade e o meio social em que estou mais diretamente inserido, ou seja, claramente envolvido em um processo de autoconhecimento.

É possível, portanto, inferir que essa modalidade de pesquisa contribui para que se tenha uma visão do indivíduo no contexto de sua vida - do nascimento até o momento de nosso encontro com ele - ou de aspectos de sua existência que interessam ao pesquisador. O sujeito é visto a partir de seu passado - com sucessos, falhas, contradições e ambiguidades - e de suas esperanças no futuro. É examinado em relação ao seu tempo histórico, assim, revelando como ele foi influenciado pelas ideias e valores religiosos, sociais, psicológicos e econômicos de seu tempo.

Plummer (2001) destaca, ainda, que as histórias de vida são úteis na geração de novas ideias e sensibilização do pesquisador para conceitos pouco explorados ou implícitos, para complementar outras estratégias de pesquisa, assim como fornecer detalhes e informações que consolidem, clarifiquem e exemplifiquem elementos teóricos.

Alguns autores que se destacam no exame da pesquisa em administração reafirmam a contribuição dessa modalidade de investigação para, parafraseando Queiróz (1991), captar-se o que acontece na encruzilhada da vida individual com a vida organizacional. 
Jones (1983), ao expor a contribuição da história de vida no campo da administração, defende que ela constitui-se numa das mais adequadas metodologias de pesquisa quando se busca verificar como as pessoas criam e relatam o mundo social ao seu redor. Seu uso possibilita o exame da estrutura interpretativa mediante a qual significados das experiências dos indivíduos acerca de suas vidas ou de segmentos específicos de seu mundo social (como, por exemplo, o mundo organizacional e as experiências de trabalho e não trabalho estudadas pelo autor) são revelados. Os relatos obtidos documentam o relacionamento entre o indivíduo e a realidade na qual ele atua, descrevem as formas utilizadas pelo sujeito para interpretar os contextos nos quais sua vida tem sido conduzida e os significados atribuídos à sua participação nesse processo, destacando-se, nesse caso, suas vivências nas empresas e em situações de trabalho.

Musson (2004), concordando com os autores citados anteriormente, reafirma que seria um erro entender a história de vida enquanto uma metodologia exclusivamente individualista. Embora ela tenha como foco experiências dos indivíduos num período de tempo, assume que tais vidas se movem ao longo da história e da estrutura social, assim, podendo abarcar o cenário mais amplo das organizações, instituições, culturas e sociedades. Ele chama atenção para o fato de que uma história de vida não pode, portanto, ser contada sem referência às mudanças históricas e sociais que a acompanham. Uma vez que mudanças estão presentes na vida das empresas, e que parte da pesquisa em administração busca entender tais processos, a história de vida pode ampliar a compreensão a respeito deles, examinando os significados que as pessoas atribuem às suas vidas durante períodos caracterizados como de mudanças e transformações vivenciados no interior das organizações.

Segundo Musson (2004), a descrição e análise de "como" as organizações funcionam envolve a compreensão das ambiguidades, incertezas e problemáticas que os indivíduos experienciam e solucionam, cotidianamente, em seu interior. Permitir que as pessoas relatem as histórias que explicitam tais contradições e momentos de indecisão indica como a socialização organizacional é construída e desenvolvida. O mesmo autor destaca, 
ainda, que a história de vida possibilita, inclusive, que o pesquisador tenha acesso às redes de relacionamento que os indivíduos acionam e/ou formam visando concretizar os papéis que eles desempenham nas organizações. Neste caso, é possível identificar quais normas, valores e experiências trazidos de outros contextos influenciam a construção e interpretação dos eventos organizacionais atuais. Para este autor, tais informações podem ser reveladoras quando se estudam temas relacionados aos fundadores, líderes e empreendedores.

Para Musson (2004) e Jones (1983), várias questões de pesquisa e temáticas podem ser investigadas usando-se a história de vida. Considerando a produção no campo da administração, destacam os seguintes temas: desenvolvimento de carreira, comportamentos e ações empreendedoras, processos de socialização, de interação social, de aprendizagem e de mobilização do conhecimento, por meio dos quais se constroem determinadas práticas de trabalho e estilos gerenciais. De acordo com Musson (2004), embora muito da pesquisa organizacional tenha foco gerencial, as organizações são compostas por diferentes grupos de pessoas com vozes que raramente são ouvidas. Assim, é possível pensar que a história de vida pode trazer contribuições quando a preocupação do pesquisador é "ouvir outras vozes", ou seja, aquelas que representam grupos minoritários e/ou historicamente excluídos das posições de poder e prestígio nas organizações.

No âmbito internacional, alguns estudos que utilizaram histórias de vida se constituem em "bons" exemplos em razão da sua qualidade acadêmica. Aqui, evidenciam-se três que estudaram o desenvolvimento de carreira, como o de Rippon (2005), que examinou a carreira de professores, e os de Woodall et al. (1995) e O'Neil e Bilimoria (2005), que focalizaram a carreira gerencial em grupos de mulheres. Um tema correlato aparece em Olesen (2001), que se preocupou em examinar a identidade profissional enquanto processo de aprendizagem. Ainda neste campo, vale a pena ressaltar a pesquisa de Connell (2007) pertinente ao trabalho intelectual conduzido por pessoas que desempenham funções que envolvem a mobilização do conhecimento, a articulação de ideias e o gerenciamento de 
relações sociais. O potencial da história de vida, também, evidencia-se nas investigações que abordaram temas relativos ao empreendedorismo, como os trabalhos de Rae $(2000 ; 2004 ; 2005)$, realizados com o objetivo de compreender como as pessoas desenvolvem habilidades empreendedoras por meio da aprendizagem.

$\mathrm{Na}$ busca por exemplos de pesquisas empíricas desenvolvidas no Brasil que utilizaram a história de vida, foi consultado o Spell - Scientific Periodicals Electronic Library - identificando-se 11 estudos: Rosa, Brito e Oliveira (2007); Margoto, Beher e Paula (2010); Feuerschütte e Godoi (2011); Teixeira et al. (2011); Carrieri e Lopes (2012); Closs e Antonello (2014a); Closs e Antonello (2014b); Alperstedt, Ferreira e Serafim (2014); Pinotti et al. (2015); Closs e Oliveira (2015); Ferreira e Godoy (2015).

O Quadro 1 elenca os temas trabalhados nessas investigações:

Quadro 1 Estudos Empíricos e Temáticas Focalizadas

EsTudos EMPÍRICOs

Teixeira et al. (2011)

Alperstedt, Ferreira e Serafim (2014)

Pinotti et al. (2015)

Closs e Antonello (2014a; 2014b)

Ferreira e Godoy (2015)

Rosa, Brito e Oliveira (2007)

Margoto, Beher e Paula (2010)

Feuerschütte e Godoi (2011)

Carrieri e Lopes (2012)

Closs e Oliveira (2015)

\section{Temáticas Focalizadas}

Empreendedorismo

Processos de aprendizagem individual e organizacional

Violência na trajetória profissional

Processo de decisão

Competências gerenciais

Organização familiar

Carreira

Fonte: Elaborado pela autora.

Em suma, pode-se inferir que os temas mais explorados nos estudos empíricos brasileiros foram: empreendedorismo e processos de aprendizagem individual e organizacional. Tais trabalhos revelam, ainda, duas possibilidades de uso da história de vida em administração. Uma, centrada em 
um só sujeito e orientada por roteiros que visam reconstituir a trajetória de vida de determinada pessoa. Outra, envolvendo um conjunto de entrevistas que se refere a experiências ou processos vividos pelos entrevistados sobre determinados interesses do pesquisador.

Para expor a respeito de algumas limitações às quais está sujeita a história de vida, destaca-se, em primeiro lugar, o alerta de Koffes (1994), segundo o qual essa metodologia envolve três dimensões: fontes de informação que relatam experiências dos sujeitos; evocações que trazem aspectos subjetivos e interpretativos construídos pelos sujeitos; e reflexões que levam à análise da experiência vivida - as quais devem ser levadas em conta pelo pesquisador de forma articulada. Segundo Koffes (1994), quando o pesquisador desconsidera essas três dimensões, pode desenvolver um relato exclusivamente objetivo, uma mera informação ou um relato totalmente subjetivo, apenas uma evocação. Nos dois casos, pode-se entender que o pesquisador limita o processo analítico-interpretativo que caracteriza essa modalidade de pesquisa.

Associada a esta questão, é relevante destacar uma segunda limitação, decorrente da situação encontrada ao examinar os estudos empíricos brasileiros publicados no SPELL. Neste caso, identificou-se o uso de textos genéricos de pesquisa qualitativa na coleta e análise dos dados, o que acaba por prejudicar e enfraquecer a qualidade da narrativa visto que os especialistas em história de vida trazem orientações específicas a respeito.

Uma terceira limitação, presente nos dias de hoje - de financiamento limitado e tempo exíguo - para a pesquisa científica, refere-se às dificuldades advindas de quando a produção não se encaixa no paradigma positivista e pós-positivista, pois tais demandas exigem um retorno mais rápido, que possa ser considerado generalizável. Considerando essa situação, Becker (1994) já destacava que:

Visto que, por estes critérios, a história de vida não produziu resultados definitivos, as pessoas têm sido incapazes de fazer alguma coisa por ela e, de modo geral, têm-se recusado a investir o tempo e o esforço necessários para obter documentos de história de vida. 
Para fechar este texto, é importante pontuar que a pesquisa que traz "novas cores e sabores" nem sempre tem sido valorizada na área da administração. No caso da história de vida, ressalta-se que, por meio de suas contribuições, elas podem promover o esforço de autorreflexão do próprio pesquisador para que ele se veja, como leciona Velho (2006, p. 17), "fazendo parte do universo social com que tenho lidado". Ao utilizar histórias de vida, ele tem a oportunidade de transformar, recontextualizar e amplificar seus conhecimentos, desse modo, podendo alterar sua forma de ver o mundo e seu próprio trabalho como pesquisador. 


\section{REFERÊNCIAS}

ALPERSTEDT, G. D.; FERREIRA, J. B.; SERAFIM, M. C. Empreendedorismo feminino: dificuldades relatadas em histórias de vida. Revista de Ciências da Administração, v.16, n. 40, p. 221-234, 2014.

ATKINSON, R. The life story interview. In: GRUBRIUM, J.A.; HOLSTEIN, J.A. Handbook of interview research: context $\&$ methods. Thousands Oaks, CA: Sage, 2001. p.121-140.

BECKER, H. Métodos de pesquisa em ciências sociais. 2. ed. São Paulo: HUCITEC, 1994.

CARRIERI, A. de P.; LOPES, F. T. "O avô constrói, o pai usa e o neto morre de fome": histórias de família em uma organização. REGE, v. 19, n. 1, p. 3-20, 2012.

CLOSS, L. Q.; ANTONELLO, C. S. Aprendizagem de gestores no contexto das transformações contemporâneas no mundo do trabalho. Revista de Ciências da Administração, v. 16, n. 39, p. 146-163, 2014a.

. Teoria da aprendizagem transformadora: contribuições para uma educação gerencial voltada para a sustentabilidade. RAM, REV. ADM. Mackenzie, v. 15, n. 3, p. 221-252, 2014b.

CLOSS, L. Q.; ROCHA-DE-OLIVEIRA, S. História de Vida e Trajetórias Profissionais: Estudo com Executivos Brasileiros. RAC Revista de Administração Contemporânea, v. 19, n. 4, p. 525-543, 2015.

CONNELL, R. Managing social relations: the dimensions of intellectual labour. International Journal of Sociology and Social Policy, v. 27, n. 1/2, p. 19-31, 2007.

DEMARTINI, Z. de B. F. Trabalhando com relatos orais: reflexões a partir de uma trajetória de pesquisa. In: LANG, A. B. da S. G. (Org.). Reflexões sobre a pesquisa sociológica. 2.ed. São Paulo: CERU, 1999. p. 33-45.

A questão da análise no processo de pesquisa. In: LANG, A. B. da S. G. (Org.). Desafios da pesquisa em ciências sociais. São Paulo: CERU, 2001. p. 49-72.

FERREIRA, J. F.; GODOY, A. S., Processos de Aprendizagem: um estudo em três restaurantes de um clube étnico alemão de negócios, gastronomia e cultura. RAM, REV. ADM. MACKENZIE, v. 16, n. 2, p.15-44, 2015.

FEUERSCHÜTTE, S. G.; GODOI, C. K. Metodologia de identificação de competências gerenciais: uma proposta com base na história de vida de gerentes seniores. Revista Alcance, v.18. n. 3, p. 321-340, 2011.

GIBBS, G. Análise de dados qualitativos. Porto Alegre: Artmed, 2009.

GODOY, A. S., Fundamentos da pesquisa qualitativa. In: TAKAHASHI, A. R. W. (Org.) 
Pesquisa qualitativa em administração: fundamentos, métodos e usos no Brasil. São Paulo: Atlas, 2013. p. 35-49.

JONES, G. R. Life history method. In: MORGAN, G. (Ed.) Beyond method: strategies for social research. Beverly Hills, CA: Sage, 1983. p. 147-159.

KOFFES, S., Experiências sociais, interpretações individuais: histórias de vida, suas possibilidades e limites. Cadernos Pagu, n. 3, p. 117-141,1994.

MARGOTO, J. B.; BEHR, R. R.; PAULA, A. P. P. de. Eu me demito! Evidências da racionalidade substantiva nas decisões de desligamento em organizações. Organizações \& Sociedade, v. 17, n. 52, p. 115-135, 2010.

MUSSON, G. Life histories. In: CASSELL, C.; SYMON, G. (Ed.) Essential guide to qualitative methods in organizational research. London: Sage, 2004. p. 34-44.

OLESEN, H. S. Professional identity as learning processes in life histories. Journal of Workplace Learning, v. 13, n. 7/8, p. 290-297, 2001.

O'NEIL, D. A.; BILIMORIA, D. Women's career development phases. Career Development International, v. 10, n. 3, p. 168-198, 2005.

PINOTTI, S. et al. Ser ou não ser empreendedor: o profissional técnico e o dilema da mudança de carreira. Revista de Empreendedorismo e Gestão de Pequenas Empresas, v. 4, n. 3, p. 177-203, 2015.

PLUMMER, K. Documents of life 2: an invitation to a critical humanism. London: Sage, 2001.

QUEIROZ, M. I. P. de. Variações sobre a técnica de gravador no registro da informação viva. São Paulo: T. A. Queiroz, 1991.

RAE, D. Understanding entrepreneurial learning: a question of how? International Journal of Entrepreneurial Behaviour \& Research, v. 6, n. 3, p. 145-155, 2000.

. Practical theories from entrepreneurs'stories: discursive approaches to entrepreneurial learning. Journal of Small Business and Enterprise Development, v. 11,n.2, p. 195-202, 2004.

Entrepreneurial learning: a narrative-based conceptual model. Journal of Small Business and Enterprise Development, v. 12, n. 3, p. 323-335, 2005.

RIPPON, J. H. Re-defining careers in education. Career Development International, v. 10, n. 4, p. 275-294, 2005.

ROSA, A. R.; BRITO, M. J. de; OLIVEIRA, F. M. de. Os sentidos da violência nas organizações: uma análise construcionista da história de vida de uma policial militar. Revista GES - Gestão \& Sociedade, v. 1, n. 1, p. 1-30, 2007. 
TEIXEIRA, R. M. et al. Empreendedorismo jovem e a influência da família: a história de vida de uma empreendedora de sucesso. REGE, v. 18, n. 1, p. 3-18, 2011.

VELHO, G. Subjetividade e sociedade: uma experiência de geração. 4. ed. Rio de Janeiro: Jorge Zahar, 2006.

WOODALL, J. et al. Winning the lottery? Organizational restructuring and women's managerial career development. Women in Management Review, v. 10, n. 3, p. 32-39, 1995. 


\section{DADOS DOS AUTORES}

\section{ARILDA SCHMIDT GODOY` arildagodoy@gmail.com}

Doutora em Educação pela Universidade de São Paulo

Instituição de vinculação: Universidade Estadual Paulista Júlio de Mesquita Filho Campus de Rio Claro (aposentada)

Sales Oliveira/SP - Brasil

Áreas de interesse em pesquisa: Competências e Aprendizagem nas Organizações.

*Avenida dos Jequitibas, 120 Jardim Guaiuvira Sales Oliveira/SP 14660-000 